\title{
Development and Validation of a Fast and Selective HPLC Method for the Determination of Amphotericin B in Nose- to-Brain Nanoliposome
}

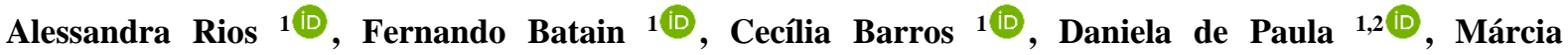 \\ Martins 1(D), Marco Chaud ${ }^{1,2,3 *}$ (D), Thais Alves ${ }^{1,3 *(D)}$ \\ 1 Laboratory of Biomaterials and Nanotechnology (LaBNUS), University of Sorocaba - UNISO, University City Campus, \\ Raposo Tavares, Vila Artura, ZC: 18023-000, Sorocaba, São Paulo, Brazil \\ 2 College of Bioprocess and Biotechnologyl Engineering, University of Sorocaba - UNISO, University City Campus, \\ Raposo Tavares, Vila Artura, ZC: 18023-000, Sorocaba, São Paulo, Brazi \\ 3 Technological Innovation Agency of Sorocaba, Sorocaba Technology Park, Itavuvu Avenue, 18078-005. Sorocaba, São \\ Paulo Brazil \\ * Correspondence: marco.chaud@ prof.uniso.br (M.C.); thaisfrancine1 @ hotmail.com (T.A.);
}

Scopus Author ID 845188500; 56710988000

Received: 20.10.2020; Revised: 17.11.2020; Accepted: 19.11.2020; Published: 22.11.2020

\begin{abstract}
A simple, fast, and selective HPLC method is presented to quantified amphotericin B (AmB) in a nose-to-brain nanoliposomal pharmaceutical formulation. The development was based on the design of experiments (DoE) approach. The chromatographic analysis was validated on a C18 Zorbax reversed-phase column (250 $\mathrm{mm} \times 4,6 \mathrm{~mm}$ I.D.) with $5 \mu \mathrm{m}$ of particle size using mobile phase, consisting of a binary mixture of ultra-purified water and an organic composition of acetonitrile, methanol, and tetrahydrofuran $(75: 17: 8, \mathrm{v} / \mathrm{v})$. The isocratic flow rate was $1.0 \mathrm{~mL} \cdot \mathrm{min}^{-1}$, and the detection at $383 \mathrm{~nm}$. The 12 minutes running time being selective between the main peak from possible degradation products, linear and accurate for the concentration range of 0.5 to $7.0 \mu \mathrm{g} \cdot \mathrm{mL}^{-1}$, and precise demonstrating a relative standard deviation of $0.01 \%(\mathrm{n}=6)$. Application of this method to assay and stability studies of AmB in nanoliposomal lipid-based is provided.
\end{abstract}

Keywords: amphotericin B; nanolipossome, high-pressure liquid chromatography; validation method, design of experiments.

(C) 2020 by the authors. This article is an open-access article distributed under the terms and conditions of the Creative Commons Attribution (CC BY) license (https://creativecommons.org/licenses/by/4.0/).

\section{Introduction}

Amphotericin B (AmB), discovered in 1953, was the first antifungal agent to be approved by the U.S. Food and Drug Administration (FDA) in 1958 [1]. The action of AmB occurs through the interaction with ergosterol, a constituent present in the fungal cell membrane, altering the selective cell permeability, with the formation of pores and consequent leakage of ions and vital substances, leading to disturbances in the enzymatic activity of the membranes and cell death [1,2]. Produced from bacterial cultures of Streptomyces nodosus, it is considered the treatment of choice in fungal infections like Cryptococcal meningitis [1,3].

With molecular formula $\mathrm{C}_{47} \mathrm{H}_{73} \mathrm{NO}_{17}$ and molecular weight of 924.08, AmB has a complex chemical structure (Figure 1). It is described as a yellow to orange powder, odorless or almost odorless, and almost tasteless, with a potency of not less than $750 \mu \mathrm{g} \mathrm{AmB} \mathrm{per} \mathrm{mg,}$ on a dry basis. Moreover, in the production of AmB, a small yield of amphotericin A (AmA) is also obtained. AmA shows less antifungal activity, and its concentration should be below 5 
$\%$, although official compendiums allow that, in formulations intended for use in the preparation of dermatological creams, lotions, and ointments, suspensions, and oral capsules, it is possible a maximum of $15 \%$ of AmA [4].



Figure 1. Molecular structure of amphotericin B.

$\mathrm{AmB}$ is poorly water-soluble in saline at a normal $\mathrm{pH}$. It shows poor membrane permeability (Biopharmaceutics Classification System class IV) [4,5]. The first technique (the 1950s) to solve the pharmacotechnical AmB problem was the formulation of AmB with the surfactant sodium deoxycholate; however, the side effects of AmB-deoxycholate formulations are hypokalemia, hypomagnesemia, anemia, and nephrotoxicity. Only then, in the 1990s, was introduced the AmB lipid formulations to the market $[5,6]$.

The nanostructures self-assemblies can cross the main barriers like the blood-brain barrier (BBB), ocular blood barrier, placental transfer, and protection against placental metabolism. Currently, some approaches allow that drugs as AmB can be vehicled in systems like stimuli-responsive systems, liposomes, and more complex structures as liquid crystal, selfemulsifying, and dendrimers that mimic those seen in biological systems [2,5-10].

The liposomes have been studied as a delivery system for AmB [2,6,11-15]. Therefore, it is necessary to evaluate the physical properties of liposomes that influence these characteristics for the quality assurance of the liposomal drug since the liposomes are normally composed of differents phospholipids and cholesterol polymers, surfactants, or proteins to surface modify [7]. Thus, it is thought that the development of an easy analytical method for liposomal drugs will lead to the provision of good-quality drugs for many patients at lower prices.

Method validation is the process of proving that an analytical method is accepted for its intended purpose [16,17]. The official compendiums describe AmB quantification in pharmaceutical products by determining the antibiotic activity (potency) demonstrated by its inhibitory effect on microorganisms; however, this onerous approach makes it difficult for laboratory analysis on a large scale. Moreover, at present, no individual pharmacopoeial monographs for the liposomal or lipid-based formulations of AmB. Nevertheless, there are some scientific publications (Table 1) that describe the quantification of AmB using chromatographic methods, as high-performance liquid chromatography (HPLC), an accurate technique that leads to faster results $[7,18-22]$. 


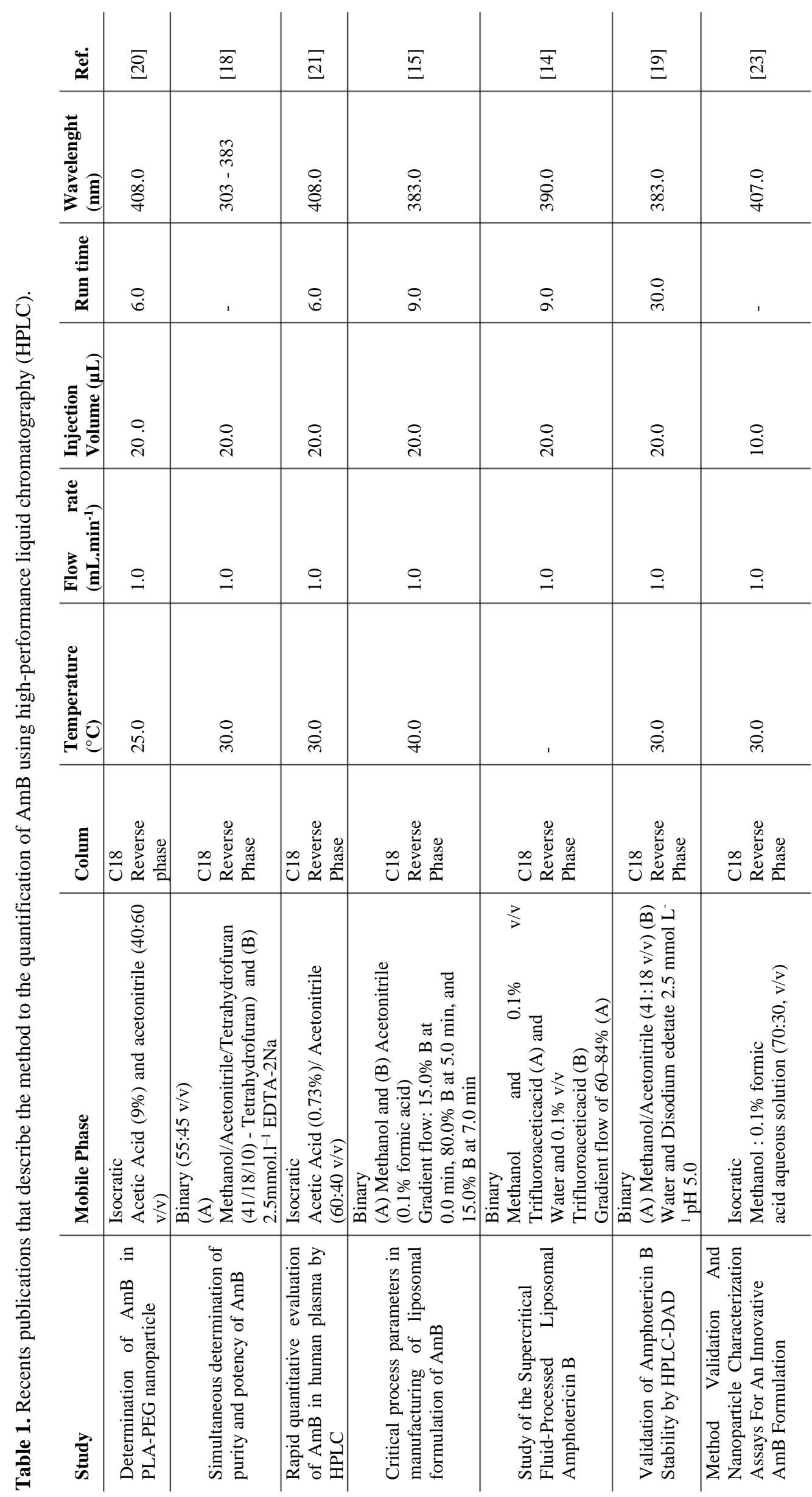


To develop a new method of drug quantification, it is necessary to know the drug features previously, as well as the formulation compounds used as its vehicle. The analytical development using a design of experiments (DoE) approach may provide better results with a few numbers of experiments through a set of statistical tools which include screening and optimization designs $[24,25]$ and was the tool of choice to develop and validate a fast and lowcost method for quantifying $\mathrm{AmB}$ in lipidic pharmaceutical dosage forms as nanoliposomal systems.

The aim of our study was to develop a rapid, robust, selective, sensitive, and precise HPLC method using the design of experiments for the determination of AmB with potential for the determination of amphotericin B in nanoliposome to nose-to-brain administration.

\section{Materials and Methods}

\subsection{Materials.}

AmB powder oral grade (purity $96.4 \%$ ) was purchased from Synbiotics Limited (Steinheim, Germany). HPLC grade acetonitrile, methanol, and tetrahydrofuran (THF) were purchased from Merck-Millipore (Darmstadt, Germany). Glacial acetic acid was purchased from Labsynth (Diadema/SP, Brazil). Ultrapure water was obtained from a Milli-Q Plus 185 system (Molsheim, France) to a final conductivity of ca. $18.2 \mathrm{M} \Omega . \mathrm{cm}^{-1}$.

\subsection{HPLC method development.}

The method was developed using a Shimadzu HPLC system (Shimadzu, Tokyo, Japan; LC-20AT Separations Module, SPD-M20A photodiode array detector - DAD). LC Solution software was used for data collections. The separation was achieved on Zorbax $\mathrm{C}_{18}(250 \mathrm{~mm}$ $\times 4.6 \mathrm{~mm}, 5 \mu \mathrm{m}$ ) column.

A simplex centroid mixtures planning was carried out to evaluate the best mobile phase composition. The aqueous portion of the mobile phase was composed of ultra-purified water. The organic modifiers evaluated in the mixture were acetonitrile, methanol, and a mixture of THF with acetonitrile $(1: 1, \mathrm{v} / \mathrm{v})$. The aqueous phase was maintained in the proportion of $50 \%$ of the total volume, while the organic solvents varied in their proportion, as described in Table 2. The Zorbax $\mathrm{C}_{18}$ column $(250 \mathrm{~mm} \times 4.6 \mathrm{~mm}, 5 \mu \mathrm{m})$, the mobile phase flow of $1.0 \mathrm{~mL}$ per minute with a room temperature of the oven, an ultra-violet detector at $383 \mathrm{~nm}$, and the injection volume of $10 \mu \mathrm{L}$ for AmB solution $\left(0.01 \mathrm{mg} \cdot \mathrm{mL}^{-1}\right)$ were kept as fixed variables. For the method optimizing the composition of the organic phase of the mobile phase that demonstrated the best resolution between the peaks of AmA and AmB associated with retention time in line to optimize the chromatographic run, was studied against the different parameters of mobile phase flow, oven column temperature, and organic phase proportion in order to obtain adequate values of asymmetry and peak purity in a factorial design 23 with triplicate of the central point. The experimental design was performed by Design-Expert ${ }^{\circledR}$ 7.0.0.

\subsection{Method optimization.}

Based on the results obtained and on the evaluation of the effects of the variables chosen for the mobile phase's organic composition, it was performed an optimization of the analytical method. It aimed to reduce the total time of the chromatographic run, with the maintenance of adequate parameters of resolution greater than 2.0 [15] between the peaks of AmA and AmB. 
Moreover, well as obtain an asymmetry factor between 0.8 and 1.5 and peak purity greater than 0.990, where the latter parameter indicates that the peak is attributed to a single component with no co-elution.

Table 2. Exploratory simplex centroid mixtures planning.

\begin{tabular}{c|c|c|c}
\multirow{2}{*}{$\begin{array}{c}\text { Random trial } \\
\text { order }\end{array}$} & \multicolumn{3}{|c}{ Organic phase } \\
\cline { 2 - 4 } & Acetonitrile & Methanol & THF:Acetonitrile (1:1, v/v) \\
\cline { 2 - 4 } & $\mathbf{( \% )}$ & $\mathbf{( \% )}$ & $(\mathbf{\%})$ \\
\hline $\mathbf{1}$ & 66.7 & 16.7 & 0.7 \\
\hline $\mathbf{2}$ & 0.0 & 100.0 & 50.0 \\
\hline $\mathbf{3}$ & 0.0 & 50.0 & 100.0 \\
\hline $\mathbf{4}$ & 0.0 & 0.0 & 50.0 \\
\hline $\mathbf{5}$ & 50.0 & 0.0 & 66.7 \\
\hline $\mathbf{6}$ & 16.7 & 16.7 & 0.0 \\
\hline $\mathbf{7}$ & 50.0 & 50.0 & 33.3 \\
\hline $\mathbf{8}$ & 33.3 & 33.3 & 0.0 \\
\hline $\mathbf{9}$ & 100.0 & 0.0 & 16.7 \\
\hline $\mathbf{1 0}$ & 16.7 & 66.7 & 0.0
\end{tabular}

(1) Corresponds to $50 \%$ of the total mobile phase.

\subsection{Validation of AmB HPLC assay.}

The HPLC method for AmB assay was validated in terms of selectivity, linearity, accuracy, and precision in the quantification of $\mathrm{AmB}$ in the presence of components of the liposome matrix, and possible degradation products were evaluated.

\subsubsection{Specificity.}

The method's selectivity was determined by comparing chromatograms obtained from the sample, placebo, and forced degradation studies. The method's selectivity was established from the resolution between the peaks closest to the AmB and through the peak purity of the drug. The forced degradation studies help identify the most susceptible degradation pathways, an intrinsic characteristic of the drug, which will even assist in studies of drug stability and the necessity of controls in the manufacturing process and storage. The forced degradation studies were performed with $\mathrm{AmB}$ at an initial concentration of $5.0 \mu \mathrm{g} \cdot \mathrm{mL}^{-1}$ which were exposed to the following conditions: i) acid hydrolysis, where $1.0 \mathrm{~mL}$ of $0.1 \mathrm{M} \mathrm{HCl}$ solution added for 30 minutes; ii) basic hydrolysis, where $1.0 \mathrm{~mL}$ of $0.1 \mathrm{M} \mathrm{NaOH}$ solution was added for 30 minutes; iii) humidity, where $1.0 \mathrm{~mL}$ of water was added for 10 minutes at $70{ }^{\circ} \mathrm{C}$; iv) thermal, in which the solution was kept at $70{ }^{\circ} \mathrm{C}$ for 10 minutes and v) photolytic, in which the solution was exposed to natural light for 60 minutes. The flasks' volume was completed with the acidified methanol (acetic acid, 1\%), homogenized, filtered through a syringe filter with a $0.45 \mu \mathrm{m}$ PVDF membrane, and analyzed using the method developed by HPLC.

\subsubsection{Linearity.}

Linearity was determined with the triplicate of seven concentration levels (range between $\left(0.5\right.$ to $\left.7.0 \mu \mathrm{g} \cdot \mathrm{mL}^{-1}\right)$ for $\mathrm{AmB}$ diluted in acidified methanol (acetic acid $1 \%$ ). The calibration curves were established by plotting the peak area versus the concentration. The regression intercept parameters and the correlation coefficient were calculated using the Excel software with the Action Stat Version 3.6 extension. 


\subsubsection{Precision.}

To assess repeatability six samples were prepared identically, with the transfer of 0.5 $\mathrm{mL}$ of the nanoliposome sample to six different $100 \mathrm{~mL}$ volumetric flasks that have been dissolved and diluted with acidified methanol (diluent). The average relative standard deviation of repeatability was $0.01 \%$, and the mean concentration was $1.11 \mathrm{mg} \cdot \mathrm{mL}^{-1}$ of AmB.

\subsubsection{Accuracy.}

The accuracy was verified with the preparation of three solutions $(0.5,5.0$, and 7.0 $\mu \mathrm{g} . \mathrm{mL}^{-1}$ ) contemplated within the linear range of the analytical method, in triplicate preparation, totaling nine sample solutions, using the developed method. The data of the experiment were statistically analyzed using Equation 1 .

[\% Recovery $=($ Recovered conc. /Injected conc. $) \times 100] \quad$ Equation 1

To study the recovery $(\%)$ and $\%$ coefficient of variance of the developed method. The mean recovery should be within $90-110 \%$ to be accepted.

\subsubsection{Robustness.}

The robustness of the method was confirmed through the experimental planning carried out in the optimization step of the method developed, where small changes were made in the composition of the mobile phase, the flow rate, and the column oven temperature.

\section{Results and Discussion}

\subsection{Method development.}

For the planning of simplex centroid mixtures (Table 1), 11 chromatographic runs, of random sequence, containing a duplicate point, with the variation of the proportion of acetonitrile, methanol, and a mixture of THF with acetonitrile (1: $1, \mathrm{v} / \mathrm{v})$ were performed. In this exploratory stage, the aqueous phase, composed of ultrapure water, was maintained at a proportion of $50 \%$ of the total volume. The data obtained were evaluated for resolution between the peaks of $\mathrm{AmA}$ and $\mathrm{AmB}$ and the retention time of $\mathrm{AmB}$. The effects were calculated using the Design Expert ${ }^{\circledR}$ software version 7.0.0 (Stat-Ease Inc., Minneapolis, MN).

As observed in Figure 2 (a) that the resolution reaches satisfactory levels with the mixture of the three organic components (central region, yellow-green color), while the shortest retention times, considering an optimized analysis, are obtained in the region where acetonitrile and the mixture of acetonitrile with THF, in Figure 2 (b), blue region. The red dots, called "Design Points", represents the actual chromatographic analyses performed in this study.

The quadratic model suggested by the software was significant for the evaluation of the retention time ( $\mathrm{p}$-value $=0.0016)$, leading to Equation 2 .

$\mathrm{RT}=+1.46 * \mathrm{~A}+216.32 * \mathrm{~B}+0.79 * \mathrm{C}-263.50 * \mathrm{AB}+37.04 * \mathrm{AC}-300.66 * \mathrm{BC}$ Equation 2

On the other hand, the model was not significant for resolution data, with p-value > 0.05. A way to improve the model would be to insert more replicates to adjust the deviation and increase degrees of freedom, but, as this study was exploratory, in order to understand the interaction between the three organic solvents, the result was considered satisfactory to follow with the optimization of chromatographic parameters. 

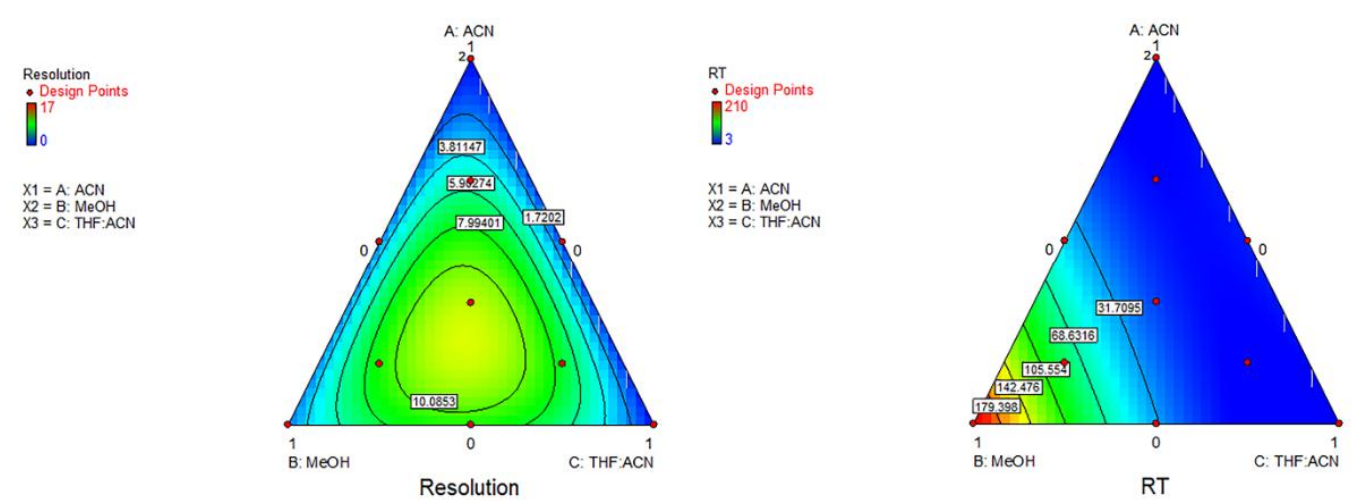

$* \mathrm{ACN}=$ acetonitrile; $\mathrm{MeOH}=$ methanol; THF: $\mathrm{ACN}=$ mixture of acetonitrile with $\mathrm{THF}(1: 1, \mathrm{v} / \mathrm{v})$; RT = retention time.

Figure 2. Effect obtained in the resolution between the peaks of amphotericin A and amphotericin B (a) and retention time $(\mathrm{RT})$ for the peak of amphotericin $\mathrm{B}(\mathrm{b})$.

\subsection{Optimized method.}

The decrease in running time is significant for faster analysis at a lower cost, as well as a reduction in waste generation. The choice of a mobile phase with a lower concentration of tetrahydrofuran also reduces the cost since it is a higher cost organic solvent compared to methanol and acetonitrile [26].

Based on the results obtained and on the evaluation of the effects of the variables chosen for the organic composition of the mobile phase, the test of choice for carrying out the optimization tests of the chromatographic parameters was experiment number 1, which presented a retention time of 7.6 minutes for AmB and resolution of 6.9 with the AmA peak, which corresponds to the main degradation product. The mobile phase's organic portion was adjusted to a proportion of $75 \%$ acetonitrile, $17 \%$ methanol, and $8 \%$ tetrahydrofuran. For this purpose, a new group of experiments was planned, through a factorial design 23 with triplicate of the central point where the independent variables evaluated were the flow of the mobile phase, the temperature of the column oven, and the portion of the organic phase, as represented in Table 3.

Table 3. Factorial design $2^{3}$ with triplicate of the central point to optimize the chromatographic condition.

\begin{tabular}{|c|c|c|c|c|c|c|c|}
\hline \multirow[b]{2}{*}{$\begin{array}{l}\text { Experiment } \\
\text { coding* }\end{array}$} & \multicolumn{3}{|c|}{ Independent factors } & \multicolumn{4}{|c|}{ Results } \\
\hline & $\begin{array}{c}\text { Flow } \\
(\mathrm{mL} / \mathrm{min})\end{array}$ & $\begin{array}{c}\text { Temperature } \\
\left({ }^{\circ} \mathrm{C}\right)\end{array}$ & $\begin{array}{c}\text { Organic phase } \\
(\%)\end{array}$ & Resolution & Asymmetry & $\begin{array}{c}\text { Peak } \\
\text { purity }\end{array}$ & $\mathbf{R T} * *$ \\
\hline 1 & 0.8 & 25 & 52 & 5.745 & 1.201 & 0.9643 & 7.563 \\
\hline 2 & 0.8 & 35 & 52 & 5.289 & 1.199 & 0.7308 & 7.048 \\
\hline 3 & 1.2 & 25 & 52 & 5.275 & 1.136 & 0.9908 & 5.118 \\
\hline 4 & 1.2 & 35 & 48 & 6.549 & 1.184 & 0.9774 & 6.420 \\
\hline 5 & 1.0 & 30 & 50 & 6.228 & 1.166 & 0.9924 & 6.787 \\
\hline 6 & 0.8 & 35 & 48 & 6.952 & 1.260 & 0.9293 & 9.380 \\
\hline 7 & 0.8 & 25 & 48 & 7.445 & 1.263 & 0.9919 & 10.083 \\
\hline 8 & 1.2 & 35 & 52 & 4.959 & 1.140 & 0.7575 & 4.783 \\
\hline 9 & 1.0 & 30 & 50 & 6.214 & 1.164 & 0.9935 & 6.777 \\
\hline 10 & 1.2 & 25 & 48 & 6.826 & 1.212 & 0.9947 & 6.911 \\
\hline 11 & 1.0 & 30 & 50 & 6.219 & 1.165 & 0.9927 & 6.777 \\
\hline
\end{tabular}

* The experiment coding corresponds to the random order of the tests. $* * \mathrm{RT}=$ retention time.

For this new set of experiments, satisfactory results were obtained for almost all chromatographic parameters, with all values greater than 2.0 for resolution, all peaks showed results within the range of 0.8 to 1.5 for asymmetry, and the retention time was low in all trials, ranging from 4.8 minutes to 10.1 minutes. The only parameter that presented unsatisfactory results in some chromatographic runs was the peak purity, where the value considered adequate 
in this research is above 0.990. Thus, segregating only the chromatographic runs that showed values greater than 0.990 purity, we can select the ideal condition based on another of the chromatographic parameters evaluated, such as peak asymmetry and retention time. The chromatographic parameters considered ideal for carrying out the AmB quantification tests in the required tests were the central point experiment, with 6.8 minutes of running time, showing resolution of 6.2 between AmA and AmB peaks, asymmetry factor of 1.16, and peak purity > 0.990. The final parameters were defined with a $250 \mathrm{~mm}$ Zorbax ODS $\left(\mathrm{C}_{18}\right)$ chromatographic column length $\times 4.6 \mathrm{~mm}$ internal diameter with $5 \mu \mathrm{m}$ particle size, oven temperature maintained at $30{ }^{\circ} \mathrm{C}$, mobile phase with isocratic elution mode, containing 50:50 (v / v) ratio of ultrapurified water and an organic solution composed of $75 \%$ acetonitrile, $17 \%$ methanol and $8 \%$, tetrahydrofuran, with a flow maintained at $1.0 \mathrm{~mL} \cdot \mathrm{min}^{-1}$, an injection volume of $10 \mu \mathrm{L}$ with ultraviolet detection in $383 \mathrm{~nm}$.

\subsection{Validation.}

Validating an analytical method means giving it validity, credibility, and confidence. The validation mainly aims to ensure that the analysis method works properly within the conditions of analysis for which it was suitable. It aims to reduce or control the factors that lead to the imprecision or inaccuracy of data generated. In the validation study, the parameters of selectivity, linearity, accuracy, and precision in the quantification of $\mathrm{AmB}$ in the presence of components of the liposome matrix and possible degradation products were evaluated.

\subsubsection{Selectivity.}

The selectivity of the method was monitored by analyzing the placebo and standard solution. No interference of excipients or degradation products was observed in the retention time of AmB (Figure 3). The peak purity of the drug was maintained above 0.9999, which represents that there was no co-elution of other peaks with the peak of interest. Thus, the method can be considered selective and indicative of stability.


Figure 3. Chromatograms obtained in the selectivity assessment. (a) Control sample; (b) Forced acid degradation; (c) Basic forced degradation; (d) Forced degradation by moisture; (e) Thermal degradation; (f) Photolytic degradation. 


\subsubsection{Linearity.}

The summary of the linearity study is shown in Table 4. Linear relationship in the concentration range of 0.53 to $7.09 \mu \mathrm{g} \cdot \mathrm{mL}^{-1}$. The residues were homoscedastic according to the Breusch Pagan test. As the correlation coefficient of 0.9995 is greater than 0.99 (as specified in national validation standards), we conclude an adequate linear relationship. The best-fit linear equation is shown in Equation 3. Thus, the method is considered linear within the specified range.

$$
\mathrm{y}=56,055.044 \mathrm{x}+415.1270 \quad \text { Equation } 3
$$

Table 4. Summary of the linearity study (Ordinary Least Squares Method).

\begin{tabular}{l|l} 
Test & Conclusion \\
\hline F test ANOVA & We do not reject the significance of the linear model \\
\hline Intercept test (Student's t-test) & Intercept equal to zero \\
\hline Pearson's Correlation Coefficient & $\mathrm{R}=0.9995$, which is bigger than the proposed (0.99) \\
\hline Residual Normality Test (Shapiro Wilk test) & We do not reject the hypothesis of normality of residuals \\
\hline Homoscedasticity Test (Breusch Pagan test) & We do not reject the homogeneity of variance of residuals \\
\hline Extreme values in the response & We do not detect extreme points \\
\hline Observation independence test (Durbin Watson test) & Observation dependency not detected
\end{tabular}

\subsubsection{Precision.}

To assess repeatability six samples were prepared identically, with the transfer of 0.5 $\mathrm{mL}$ of the nanoliposome sample to six different $100 \mathrm{~mL}$ volumetric flasks that have been dissolved and diluted with acidified methanol (diluent). The average relative standard deviation of repeatability was $0.01 \%$, and the mean concentration was $1.11 \mathrm{mg} \cdot \mathrm{mL}^{-1}$ of AmB.

\subsubsection{Accuracy.}

The accuracy was verified with the preparation of three solutions contemplated within the linear range of the analytical method, in triplicate preparation, totaling nine sample solutions. The value of recovery $(\%)$ and $\%$ coefficient of variance, indicating method accuracy, is listed in Table 5.

Table 5. Data obtained for amphotericin B accuracy.

\begin{tabular}{|c|c|}
\hline Level & AmB recovery $(\%)$ \\
\hline \multirow{3}{*}{$\begin{array}{l}\text { Low } \\
\left(\approx 0.5 \mu \mathrm{g} . \mathrm{mL}^{-1}\right)\end{array}$} & 100.6 \\
\hline & 99.9 \\
\hline & 99.8 \\
\hline \multirow{3}{*}{$\begin{array}{l}\text { Medium } \\
\left(\approx 5.0 \mu \mathrm{g} . \mathrm{mL}^{-1}\right)\end{array}$} & 99.7 \\
\hline & 101.6 \\
\hline & 99.4 \\
\hline \multirow{3}{*}{$\begin{array}{l}\text { High } \\
\left(\approx 7.0 \mu \mathrm{g} . \mathrm{mL}^{-1}\right)\end{array}$} & 98.8 \\
\hline & 101.3 \\
\hline & 100.9 \\
\hline Average $(\mathbf{n}=9)$ & 100.02 \\
\hline Coefficient of variance $(n=9)$ & $0.93 \%$ \\
\hline
\end{tabular}

\subsubsection{Robustness.}

The robustness of the method was confirmed through the experimental planning carried out in the optimization step of the method developed, where small changes were made in the composition of the mobile phase, the flow rate, and the column oven temperature. The altered parameters did not affect chromatographic parameters important in quantification such as resolution and asymmetry (Table 3); therefore, the method can be considered robust. 


\section{Conclusions}

In this research effort, the development and validation of a simple, fast, and selective HPLC method to quantified amphotericin B (AmB) in a nose-to-brain nanoliposome pharmaceutical formulation had been investigated. The short retention time of 6.8 minutes and the selective ability to separate the main peak from degradation products allows the analysis of a large number of samples to check the quality of drugs during the monitoring of bulk sample and stability studies in pharmaceutical formulations. The validated HPLC method is showing satisfactory data for good performance for AmB quantification.

\section{Funding}

This work was supported by the Technological Innovation Agency of Sorocaba Technology Park, National Council for Scientific and Technological-Brazil (CNPq grant number: 425271/2016-1), São Paulo Research Foundation (FAPESP grant numbers: 2011/21219-5), and University of Sorocaba (UNISO), São Paulo, Brazil.

\section{Acknowledgments}

Universidade de Sorocaba. Parque Tecnológico de Sorocaba

\section{Conflicts of Interest}

The authors declare no conflict of interest.

\section{References}

1. Al-Khikani, F.H.O. Amphotericin B from antifungal to antiviral therapy: Promising modern therapeutic branch. Res. Results Pharmacol. 2020, 6, 57-65, https://doi.org/10.3897/RRPHARMACOLOGY.6.53649.

2. Mosimann, V.; Neumayr, A.; Paris, D.H.; Blum, J. Liposomal amphotericin B treatment of Old World cutaneous and mucosal leishmaniasis: A literature review. Acta Trop. 2018, 182, 246-250, https://doi.org/10.1016/j.actatropica.2018.03.016.

3. World Health Organization. Guidelines for the diagnosis,prevention and management of cryptococcal disease in HIV- infected adults, adolescents, and children; 2018.

4. USP 43 -NF38, U. S. pharmacopeia- Amphotericin B 2007, 29, 164.

5. Chaud, M.V.; Rios, A.C.; Dos Santos, C.A.; De Barros, C.T.; De Souza, J.F.; Alves, T.F.R. Nanostructure self-assembly for direct nose-to-brain drug delivery: A novel approach for cryptococcal meningitis. In: Nanomycotoxicology: Treating Mycotoxins in the Nano Way. 2019; pp. 449-480, https://doi.org/10.1016/B978-0-12-817998-7.00019-7.

6. Shirzadi, M.R. Lipsosomal amphotericin B: a review of its properties, function, and use for treatment of cutaneous leishmaniasis. Res. Rep. Trop. Med. 2019, 10, 11-18, https://doi.org/10.2147/rrtm.s200218.

7. Kato, M. Overview of the state-of-the-art liposomal drug analysis using high-performance liquid $\begin{array}{lllll}\text { chromatography. } & \text { Appl. } & \text { Spectrosc. } & \text { Rev. } & \text { 2018, }\end{array}$ https://doi.org/10.1080/05704928.2017.1323308.

8. Khan, M.; Nadhman, A.; Shah, W.; Khan, I.; Yasinzai, M. Formulation and characterisation of a selfnanoemulsifying drug delivery system of amphotericin B for the treatment of leishmaniasis. IET Nanobiotechnology 2019, 13, 21-27, https://doi.org/10.1049/iet-nbt.2018.5281.

9. Wang, J.; Shi, R.-X.; Sun, R.-G.; Hao, C.-C.; Li, J.-H.; Lu, X.-L. Influence of amphotericin B on liquid crystal state of the Cholesterol/Dipalmitoylphosphatidylcholine monolayer in the presence of different metal cations. Chinese Phys. B 2016, 25.

10. Jahadi, M.; Khosravi-Darani, K.; Ehsani, M. R.; Pimentel, T.C.; Cruz, A.G.; Mozafari, M.R. Accelerating ripening of Iranian white brined cheesesusing liposome-encapsulated and free proteinases. Biointerface Res. Appl. Chem. release profile 2020, 4966-4971, https://doi.org/10.33263/BRIAC101.966971.

11. Nisini, R.; Poerio, N.; Mariotti, S.; De Santis, F.; Fraziano, M. The multirole of liposomes in therapy and prevention of infectious diseases. Front. Immunol. 2018, 9, https://doi.org/10.3389/fimmu.2018.00155. 
12. Adler-Moore, J.; Lewis, R.E.; Brüggemann, R.J.M.; Rijnders, B.J.A.; Groll, A.H.; Walsh, T.J. Preclinical Safety, Tolerability, Pharmacokinetics, Pharmacodynamics, and Antifungal Activity of Liposomal Amphotericin B. Clin. Infect. Dis. 2019, 68, S244-S259, https://doi.org/10.1093/cid/ciz064.

13. Van Haute, D.; Jiang, W.; Mudalige, T. Evaluation of size-based distribution of drug and excipient in amphotericin B liposomal formulation. Int. J. Pharm. 2019, 569, https://doi.org/10.1016/j.ijpharm.2019.118603.

14. Lim, C.B.; Abuzar, S.M.; Karn, P.R.; Cho, W.; Park, H.J.; Cho, C.W.; Hwang, S.J. Preparation, characterization, and in vivo pharmacokinetic study of the supercritical fluid-processed liposomal amphotericin B. Pharmaceutics 2019, 11, 1-18, https://doi.org/10.3390/pharmaceutics11110589.

15. Rivnay, B.; Wakim, J.; Avery, K.; Petrochenko, P.; Myung, J.H.; Kozak, D.; Yoon, S.; Landrau, N.; Nivorozhkin, A. Critical process parameters in manufacturing of liposomal formulations of amphotericin B. Int. J. Pharm. 2019, 565, 447-457, https://doi.org/10.1016/j.ijpharm.2019.04.052.

16. Logoyda, L. LC-MS/MS Method Development and Validation for the Determination of Nifedipine in Human Plasma. Biointerface Res. Appl. Chem. 2020, 10, 6189-6196.

17. Swapna, B.; Kiran, G.; Vasudha, B.; Rajendra Kumar, J. Stability indicating RP-HPLC method for simultaneous estimation of betamethasone dipropionate and calcipotriene in bulk and pharmaceutical dosage form. Biointerface Res. Appl. Chem. 2018, 8, 3089-3094.

18. Chang, Y.; Wang, Y.H.; Hu, C.Q. Simultaneous determination of purity and potency of amphotericin B by HPLC. J. Antibiot. (Tokyo) 2011, 64, 735-739, https://doi.org/10.1038/ja.2011.83.

19. Montenegro, M.; de Souza, S.; Leão, R.; Rocha, H.; de Rezende, C.; de Souza, R. Methodology Development and Validation of Amphotericin B Stability by HPLC-DAD. J. Braz. Chem. Soc. 2020, 31, 916-926, https://doi.org/10.21577/0103-5053.20190256.

20. Rodrigues, C.D.; Khalil, N.M.; Mainardes, R.M. Determination of amphotericin B in PLA-PEG blend nanoparticles by HPLC-PDA. Brazilian J. Pharm. Sci. 2014, 50, 859-868, https://doi.org/10.1590/S198482502014000400021.

21. Balabathula, P.; Janagam, D.R.; Mittal, N.K.; Mandal, B.; Thoma, L.A.; Wood, G.C. Rapid quantitative evaluation of Amphotericin B in human plasma, by validated HPLC method. J. Bioequivalence Bioavailab. 2013, 5, 121-124, https://doi.org/10.4172/jbb.1000145.

22. Eldem, T.; Arican-Cellat, N. High-performance liquid chromatographic determination of amphotericin B in a liposomal pharmaceutical product and validation of the assay. J. Chromatogr. Sci. 2000, 38, 338-344, https://doi.org/10.1093/chromsci/38.8.338.

23. Tadini, M.C.; de Freitas Pinheiro, A.M.; Carrão, D.B.; Aguillera Forte, A.L.S.; Nikolaou, S.; de Oliveira, A.R.M.; Berretta, A.A.; Marquele-Oliveira, F. Method validation and nanoparticle characterization assays for an innovative amphothericin B formulation to reach increased stability and safety in infectious diseases. J. Pharm. Biomed. Anal. 2017, 145, 576-585, https://doi.org/10.1016/j.jpba.2017.06.034.

24. Vera Candioti, L.; De Zan, M.M.; Cámara, M.S.; Goicoechea, H.C. Experimental design and multiple response optimization. Using the desirability function in analytical methods development. Talanta 2014, 124, 123-138, https://doi.org/10.1016/j.talanta.2014.01.034.

25. Politis, S.N.; Colombo, P.; Colombo, G.; Rekkas, D.M. Design of experiments (DoE) in pharmaceutical development. Drug Dev. Ind. Pharm. 2017, 43, 889-901, https://doi.org/10.1080/03639045.2017.1291672.

26. Da Silva, C.G.A.; Collins, C.H. Super/subcritical fluid chromatography with packed columns: State of the art and applications. Quim. Nova 2014, 37, 1047-1057, https://doi.org/10.5935/0100-4042.20140158. 